\title{
The Emergence of Leadership within Networks of Local Development
}

\section{Actors}

\author{
Hervé Stecq ${ }^{1}$ \\ ${ }^{1}$ Department of Humanities, University of Quebec at Chicoutimi, Chicoutimi, Quebec, Canada \\ Correspondence: Hervé Stecq, Department of Humanities, University of Quebec at Chicoutimi, 555 boul. Université, \\ Chicoutimi,QC., G7H 2B1, Canada. Tel: 1-418-817-3463. E-mail: herve.stecq@uqac.ca
}

Received: August 18, 2014 Accepted: August 30, $2014 \quad$ Online Published: September 15, 2014

doi:10.5430/wjss.v2n1p24 URL: http://dx.doi.org/10.5430/wjss.v2n1p24

\begin{abstract}
Networks of local development actors are subject to several dynamics. One of them, the emergence of leadership, highlights mechanisms articulating both the structure and the individual actor. Leadership is not just an individual attribute, but also a capital in a network. Leadership cannot emerge ex nihilo; it requires a number of interpersonal interactions. This is how leadership is structuring, while starting a virtuous circle. It will be all the more underlined as some leaders are themselves actors in the emergence of leadership. They will be the instigators of various types of interactions in their networks. Finally they embody various roles, which will impact the level of emergence of leadership.
\end{abstract}

Keywords: Cooperation network, emerging leadership, interactions, local development actors

\section{Introduction}

\subsection{Introduction to the Problem}

Leadership has emerged as a mobilizing influence of local development actors' networks, as well as the organizational discourse (Stecq). So to be activated, each network must therefore have a leadership. Organizational leadership has many dimensions. It may either be the sum of individuals' leadership, or a holistic leadership which transcends each individual. A distinct paradigm focused on the conditions of emergence of leadership within a network or an organization (Barker, 1991). Those conditions are still little known, since the interactions causing the emerging process were not clearly identified. More recent studies have revealed types of relationships that make a leadership emerge. These are in order of influence: mentoring, coaching, relay and challenge (Luc, 2004). In this study, we intend to verify the role of these types of relationships in the emergence of leadership. We assume that leaders are involved in these relationships. In choosing the type of relationship, they can influence the level of emergence of leadership in their network. For example, as a mentor a leader will contribute to a higher level of emergence of leadership; more than if he was just a challenger. The leader therefore shares his leadership. The assumption is that the more leadership is shared, the more likely it is to emerge within networks of actors. Before making the empirical demonstration, it will be necessary to define the main concepts in the study: local development actors' network and emerging leadership.

\subsection{Local Development Actors' Network}

Local development actors are subjects, that is to say individuals who "appropriated their own experience" (Touraine, 1992, p. 267). They are individuals or a collective, or both simultaneously (Gumuchian, Grasset, Lajarde and Roux, 2003). They belong to several social spheres: civil society, local authorities, entrepreneurs, trade unions, social groups, etc. (Friedmann, 1992). Local development actors shape their territorial reality (Lefebvre 1974). A strategic territory is then called a "milieu", namely a "localized set formed by integrated networks" (Joyal, 2002, p. 47). The networks formed by local development actors are networks of mobilization and cooperation. A mobilization network is that "where actors mobilize relationships they have with others in order to exercise joint control, [...] or unilateral control (to their advantage) [...]" (Lemieux, 1999, p. 77). Cooperation networks are those which "do not oppose opponents, but [which] are rather made of stakeholders who seek to cooperate with each other" (Ibid., p. 78). 


\subsection{Emerging Leadership}

There are many definitions of leadership. Most relevant to our study is the one that underscores the importance of influence: "Leadership is an act of influence, voluntarily accepted by the group, which directs a group known to its goals and that keeps the group as a group" (Barker, Wahlers and Watson, 1987, p. 153). Leadership has a local base. Thus, local leadership is "a process shared between one or more leaders and a community at a time and in a given context. The real leader influences the culture of his or her community to the point of becoming social architect and introducing new values" (Prevost, 1996, p. 6).

Leadership has two aspects: one operative, the other emotional and affective (Aebischer and Oberlé, 2007). They are sometimes called behavioral aspect and emotional aspect (Wils, Labelle, Guérin and Tremblay, 1998). There are also several dimensions of leadership when it is embedded in a network or in an organization. According to the individual approach, organizational leadership is the sum of individual leaderships. Conversely, the holistic organizational leadership is global. Finally, leadership can be seen as an interpersonal influence process. In that approach, leadership practices are characterized by the emergence of individual leadership. Actors are in situations of interpersonal communication, during which leadership is built.

The paradigm of emerging leadership matches an interactional approach, as relationships cause the emergence of leadership. The people behind this process are referred to as "leadership updating actors" (Luc, 2004, p. 93). There are six types of them: the mentor, the coach, the challenger, the relayeur (Note 1), the inspiring model and the anti-model (Ibid., p 96..). When they embody one of these roles, leaders choose a participative style (i.e. shared leadership) (Forsyth, 1990). The interactional approach will be privileged in this study to analyze the emergence of leadership within networks of local development actors.

\section{Materials and Methods}

\subsection{Case Study}

A case study is "an empirical inquiry that investigates a contemporary phenomenon within its real-life context, especially when the boundaries between phenomenon and context are not clearly evident" (Yin, 2003, p. 13). The choice of the case study method is justified by the desire to put forward a context surrounding the phenomenon known in the question and in the research hypothesis (Roy, 2009). The case must be expanded by increasing the number of data sources, quantitative or qualitative, secondary or primary. For example, semi-structured interviews are essential in building a case.

The MigrAction Strategy in the Saguenay - Lac-Saint-Jean, a region of northern Quebec, will be the case studied. It is described as a "specific agreement to positively influence net migration of young people in the Saguenay Lac-Saint-Jean." It was concluded on June 25, 2004 between 15 stakeholders. But the MigrAction Strategy was originally created on September 15, 2003 at the initiative of youth organizations in the Saguenay - Lac-Saint-Jean, in order to counter youth migration. The renewal of the specific agreement was formalized on July 14, 2008, this time for five years with 36 stakeholders. The MigrAction Strategy is called "global strategy" because of its transversal areas of intervention, both in the economic and social fields. Since the causes of the youth migration phenomenon are diverse, solutions will logically be varied. The MigrAction Strategy has five intervention targets.

To be selected, a case will demonstrate its exemplary (Yin, 2003, pp. 160-162). The MigrAction Strategy is exemplary because it is complete, in addition to illustrate the phenomenon of emerging leadership in a network. First, the MigrAction Strategy can be exhaustively documented. Various sources of information were used to build the case and develop a substantial territorial context. The data have been triangulated. Secondary, data from multiple sources and types were used: organizational reports, articles from local and regional newspapers, press releases, and statistics from the Institut de la Statistique du Québec (ISQ) and Statistics Canada.

The researcher found that the MigrAction Strategy was particularly publicized through the local and regional press. A press review was formed in the study period from 2001 to 2011. October 27, 2001 is a key date in the building of the MigrAction Strategy, because during the Regional Youth Rally organizations decided to tackle the youth migration issue. The research period was concluded in June 2011, when the annual review of the Strategy MigrAction was made to donors. The use of the software retrieval, Eureka.cc, guaranteed the completeness of the press review. After screening, 446 articles were retained for their relevance.

\subsection{Sample Size for Semi-structured Interviews, Power and Precision}

An interview outline was formed to collect information on the emergence of leadership within the network of youth 
organizations participating in the MigrAction Strategy. The choice of a case study involves a population and not a sample in the statistical sense. This population is often "included in the definition of the object" (Blanchet and Gotman, 2006). The designated population is thus all persons working, or who have worked, in youth organizations involved in the MigrAction Strategy. A press review has been helpful to distinguish key persons. A core group of 13 people was then established. To complete the population, the researcher conducted the snowball sampling method, "a technique that involves adding to a core of individuals, all those who come into contact with them, and so on" (Beaud, 2009, p. 266). For example several interviewees have referred us to some of their colleagues. Finally, the population was formed by 23 individuals (Note 2).

The interviews were in accordance with the ethical rules as formulated by the Ethics and Research Committee (ERC) of the University of Quebec at Chicoutimi (UQAC). An ethics certificate was granted on February 13, 2011. A consent form was signed by the research subjects, who have been warned of the objectives, benefits and risks of the research, confidentiality rules and dissemination of results, and finally the modalities for their participation. Note that to preserve the anonymity of participants, the names used are fictitious.

\subsection{Methods of Analysis}

All recorded interviews were fully transcribed. The transcript was then coded. Initially, the researcher divided the corpus in "predications", as indicated by the rules of the "discourse predication analysis" (DPA) (Ghiglione, Matalon et Bacri, 1985). An average of just over 400 predications by interview was reached. As the preferred analysis is categorical, these predications were subsequently grouped under the cap of a common theme. The researcher identified the units of information inherent to the types of interactions: mentoring, coaching, relay, challenge, inspiring model and anti-model.

The analysis of leadership practices within the MigrAction Strategy began with the formation of networks. The most recurrent individuals in the discourse were potential leaders, and were studied as such. The most listed in order of importance were: Pierre, Irène, Sonia and Jeanne. A matrix was built with Ucinet 6 . Relationships and ties were marked with a "1" in the matrix. The network was represented by a graph obtained by NetDraw (Figure 1).

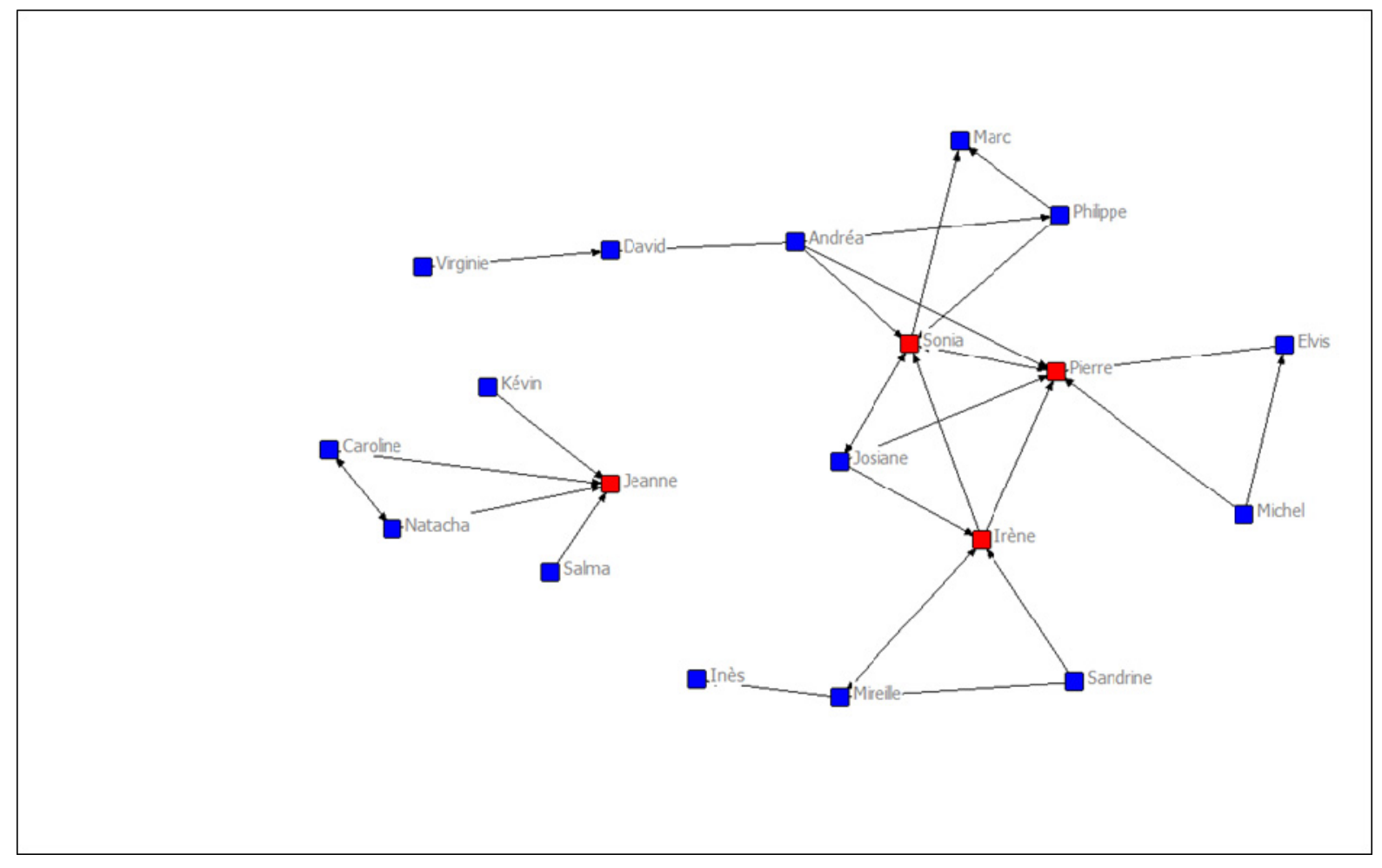

Figure 1. The MigrAction Strategy members' network 


\section{Results}

\subsection{Interactions between Actors}

Interacting situations between actors can be characterized as "structural-temporal", in so far as their context is both structural and temporal. The first specifies intra-organizational and inter-organizational interactions, while the second reframes them through time.

\subsubsection{Intra-organizational Interactions}

Intra-organizational interactions are explained through the example of the Regroupement action jeunesse-02 (RAJ-02) (Note 3), one of the four youth organizations involved in the MigrAction Strategy. Many interactions are manifested between actors of the MigrAction Strategy. Different people come together: board members and permanent employees responsible of operationalizing the MigrAction Strategy. Hence the existence of three potential kinds of interactions: between board members, between permanent employees and board members, between permanent employees.

First, the Board of Directors is a champion of interactions that materialize at bimonthly or monthly meetings. It is an example for many reasons. First, it brings together 19 members of various ages and aspirations. On the other hand, it is dynamic despite the voluntary involvement of its board members. Secondly, the Board of Directors and the Director of the RAJ-02 were in constant communication in achieving the MigrAction Strategy, especially when the President of the Board and the Director of the RAJ-02 worked together. Finally, interactions occurred between permanent employees.

\subsubsection{Inter-organizational Interactions}

As a regional body, the Conférence régionale des élus (CRÉ) (Note 4) fosters inter-organizational interactions at a regional scale. Several bridges exist between it and the RAJ-02. First, the RAJ-02 is an advisory body to the CRÉ on youth issues. Therefore, many of its members sit at the table of regional representatives. On the other hand, representatives of the CRÉ are responsible for youth issues, which causes them to be in touch with members of the RAJ-02.

Committee meetings are other opportunities for inter-organizational interactions. The heterogeneity of the MigrAction Strategy (i.e. from various youth organizations) is likely to pose problems of coordination and cohesion. Hence the creation of a coordinating committee. In addition, the Coordinating Committee has to facilitate the coordination work of the Director, who must manage human resources. The Monitoring Committee and the Evaluation Committee meet annually to assess the impacts of the MigrAction Strategy. It is a process of accountability among donors.

Roundtables are other places of inter-organizational interactions. The "migrActive" tables bring together many stakeholders who consult on actions in their communities, in order to influence net migration of young people. They are designed to maintain a local mobilization around the targets of the MigrAction Strategy. They facilitate a dialogue with parties that have traditionally little contact with each other and have different views and ways of working.

\subsubsection{Temporal Context of Interactions}

The actors of the MigrAction Strategy were sometimes interacting with political representatives at information or consultation meetings. Suggestions made by young people have led to collaborations. The best example is the mobilization for the tax credit for new graduates in remote regions, result of negociations with the government.

Youth gatherings are events rich in interactions. They contain a double dynamic. First, the Regional Youth Rally is a consultative event. Debates are organized in the form of thematic workshops to gather the views of young people on various issues. The RAJ-02, voice of youth in the Saguenay - Lac-Saint-Jean, was instructed to communicate all of these concerns to regional decision makers through discussion reports. On the other hand, a discourse is diffused to the young people present at the event, to instill the desire to get involved.

"Missions" are actions that involve actors to interact. They are conducted in spheres of interactions which are unfamiliar: either a territory or an organizational environment. Missions can for example be conducted in local schools to maintain a sense of belonging, as desired by the fifth target of the MigrAction Strategy. They may also be missions outside of the region. Many of them were motivated by a transfer of expertise to other regions hoping to adopt a similar strategy to that of MigrAction.

The structuring stages of the MigrAction Strategy resulted in many "cyclical" interactions. The signature of the 
specific agreement was the culmination of successive meetings which purpose was to convince potential stakeholders. The creation of migrActive roundtables constitutes other cyclical interactions. It was indeed necessary to create a consensus to expect a strong local mobilization around the issue of youth migration. The phases of renewal of the specific agreement produced in turn a multitude of interactions. Renewing means negotiating. Networking is then necessary. Negotiations were undertaken with stakeholders already committed or those who could be.

\subsubsection{Less Formal Interactions}

Finally should be mentioned the "less formal" interactions. They are collaborations led by actors in the course of carrying out their duties. Indeed, collaboration has a lesser degree of formality compared to partnership (Bourque, 2008). There are multiple collaborative circles: 1) between members of the field team of MigrAction; 2) between stakeholders of the specific agreement; 3) with non-members of the MigrAction Strategy.

The first recorded collaborations are those happening between members of the field team, precisely all the representatives of the youth organizations conducting fieldwork. These collaborations are often made outside committees and bi-monthly meetings, often for the purposes of agents requesting special assistance in carrying out their daily tasks. The second sphere, wider, refers to the collaboration between the stakeholders of the MigrAction Strategy. It may include: ministerial stakeholders, local policymakers, local representatives, etc. These collaborations are more or less formal. The existing closeness in tight circles means a set of relationships in networks. The third sphere is that of collaborations with non-members of the MigrAction Strategy. This collaboration, somehow pragmatic, takes place within the networks built by the actors.

A few remarks can be raised. First, the three spheres of collaboration overlap within these networks. Then this networking is associated with a gain of experience in teamwork, that is to say a better understanding of collaborators. Finally, the mobilization of personal networks is useful to achieve one's daily tasks.

\subsection{The Role of Leaders in Emerging Leadership}

\subsubsection{Mentoring}

The mentor's function is to direct and guide. He or she helps to anchor the aspiring leaders in their "values" and "warn them [...] about strategic choices of lifestyle and career" (Luc, 2004, p. 111). The relationship between Sonia, Pierre and Marc, could be about mentoring. They have directed Sonia in anchoring her values, leading her to a shift in her career choices. She decided to be a development officer instead of a representative in the pharmaceutical industry. Pierre's mentoring also confirmed Sonia in defining her professional profile. She built herself as a pragmatic person, an administrator operationalizing a utopia designed by Pierre the sociologist.

\subsubsection{Coaching}

The coach's mission is to educate. He or she provides: a development of specific skills; greater confidence in decision making; support at critical times (Luc, 2004, p. 111). The relationship between Mireille and Irene could be similar to that of student and coach. Irène was aware of her role as a coach to Mireille. This supervision could have consolidated Mireille in her decision-making thanks to the leeway she had, which was received as a sign of confidence. Having held the position of Mireille before, Irène may accompany her in critical moments, when the limits of her competences were being felt.

\subsubsection{Relaying}

The relayeur is defined as the one who "provides access to people, experiences, information" (Luc, 2004, p. 111). In our study, we find that the potential relayeurs held the positions of those they pass the relay to. Irène was a development officer before Mireille. David was an agent of participation before Virginie. They are holders of information they can pass on to their successors. Such relay could therefore contribute to skills development. The transmission of information ensures better access to key positions, thus useful experience to the emergence of leadership. For example when leaving office, David sent to Virginie a job offer as a participation officer.

\subsubsection{Challenging}

The challenger will challenge to excel. He or she helps to: accelerate skills development; develop one's self-confidence; increase one's ability to take some calculated risks; get out of the routine (Luc, 2004, p.111-112). The most obvious case of challenging interaction could be that narrated by Sonia. The emergence of Sonia's leadership could have been the work of the "team" which made her aware of the role she was to hold in the MigrAction Strategy. The team embodied the challenger, inviting Sonia to take her responsibilities and meeting her challenges. The result was an increase in self-confidence. 


\subsubsection{Role-models}

The role-model is a figure that inspires. In the case of our study, it will be regional models, more or less accessible, quiet, familiar or publicized. Role-models are inspirations that we listen, observe, and even imitate. They help others to be rooted in their own values, to learn new skills or new behaviors (Luc, 2004, p. 112).

The Regional Prevention Center of School Dropout (CRÉPAS) is cited as a model by the actors of the MigrAction Strategy for several reasons. First, it is a specific agreement for youth, prior to the MigrAction Strategy. This makes it a precursor. Second, it brought together regional partners, thus offering an example of harmonious collaboration. Finally, the professionalism of the CRÉPAS is praised, particularly its ability to assess the impact of its actions.

The figure of the young politician is appreciated by several members of the MigrAction Strategy. These young politicians are examples of involvement, role models for all young people who want to make a change. Their youth brings a local drive or a development. Ultimately, their political involvement could have benefited all the other young people.

Finally, examples of entrepreneurs in the region are named. Youth entrepreneurship, subject of the fourth target of the MigrAction Strategy, remains a major challenge in the Saguenay - Lac-Saint-Jean, where the index of entrepreneurial activity is one of the lowest in Quebec (Proulx, 2007). Thus, entrepreneurs are pointed out as examples. These models are also a source of pride.

\subsubsection{Anti-models}

Some local politicians appear as anti-models. Primarily, they are blamed for their bigotry, otherwise called "turf war", which would make impossible any collective action at the regional level. This attitude was not without confusing the actors of the MigrAction Strategy, who are in charge of promoting regional unity meaningful to the realization of a comprehensive strategy. That bigotry could be a counter-example not to be emulated by the youth organizations which wanted to distance themselves by presenting an alternative. According to Pierre, the youth of some actors had been an asset to break that counter-example of mobilization. Ultimately, the youth organizations have had the conviction to have been models at odds with anti-models. The lack of local development vision by some local officials, could have been another irritant helping to shape their image of anti-models.

The media is cited as the second figure of anti-model. Their defeatism might be questioned because of their propensity to relay pessimistic news. Defeatism, often associated with sensationalism is likely to harm the sense of belonging, oh so useful for the return of young people. They could be conditioned early to migrate because of a negative image of the region in the media.

\section{Discussion}

Several conclusions will be drawn from the study of the emergence of leadership within the MigrAction Strategy: one on shared leadership, another on the temporal and structural frameworks of personal leadership, the last one on the periods of leadership.

\subsection{Shared Leadership}

Actors contributing to the emergence of leadership among individuals forming the MigrAction Strategy, are themselves leaders. Pierre and Irène were respectively mentor and coach for Sonia and Mireille. These former are thus "participative leaders" (Forsyth, 1990). Indeed, a participative leader collaborates or delegates more often. He or she "consults his or her subordinates, solicits ideas and opinions into account when making his or her decisions" (Lainey, 2008, p. 126). This leadership "inspires, motivates and encourages people to be performing" (Ibid., p. 193). In short, it is the antithesis of autocratic leadership. Several features are clearly identified: the ability to solicit ideas, taking into account the views and motivation of the staff. These are precisely the roles played by Pierre and Irène when they were mentor and coach.

\subsection{Structural and Temporal Frame}

Some conclusions can be drawn about the temporal and structural frameworks. Interactions may manifest more in a continuous time frame than in a punctual one. Indeed, the significant interactions favoring the emergence of leadership were in everyday relationships, rather than during special events. On the other hand, leadership may rather form in intra-organizational relationships. This ultimately means that proximity between actors promotes continuous emergence of leadership. 


\subsection{Level of Emerging Leadership}

The first period of emerging leadership, from 2004 to 2006, is one when Pierre (2001-2006), Marc (2002-2007) and Sonia (2004-2008) were simultaneously actors of the MigrAction Strategy. This period of emerging leadership may be considered high, since it is characterized by a mentoring relationship. The period from 2007 to 2010 was marked by a cooperation between David and Virginie. David was a relayeur to Virginie, giving her access to the RAJ-02, to the delight of the latter. The influence of a relationship based on relay is less intense than that relying on mentoring, being more technical than spiritual. Thus, interpersonal interactions during the period from 2007 to 2010 might have been lower than between 2004 and 2006. The last period, from 2010 to 2011, is characterized by a coaching interaction type for personal skills development. Irène (2001-2011) was a coach to Mireille (2010-2011) who took over as a migration officer for the MigrAction Strategy. She was helped by the former in the performance of her duties, giving her de facto greater confidence in decision making. The influence of coaching is higher than that of relay since it shapes the personality of the "coachee".

In summary, the first period, from 2004 to 2006, may have showed the strongest emergence of leadership. The second period, between 2007 and 2010, was deemed to be less intense. A third period, taking shape between 2010 and 2011, may have been stronger than the second one, but less intense than the first one.

\section{Conclusion}

It was first demonstrated that interactions have a structural context, either intra-organizational or inter-organizational (committees, roundtables, etc.), and a temporal context (event or cyclical). Local and regional actors have shown through their practice, the existence of several spheres of interactions that transcend structural frames. In addition, the degree of formality of interactions is variable, so that they take the form of collaborative networks.

On the other hand, should be remembered three areas of interpersonal dynamics: between Pierre, Marc and Sonia; between Irène and Mireille; between David and Virginie. The first relationship was a mentoring, the second a coaching and a relay and the third one a relay only. These relationships were temporally ordered to identify periods of high emergence of leadership. Then, it should be noted that the same people had multiple functions as actors updating leadership, contributing in many ways to its emergence. Finally, these actors can be collectives: groups, organizations, partnerships, etc.

Studies of small groups like ours, have several limitations. They can hardly be generalized as specific contexts can influence the variables. The pattern of emerging leadership and of types of relationships can vary significantly from one situation to another, depending on: the personalities of the people involved, the type of organization, the theme of mobilization or the level of mobilization of the community. These are factors which may therefore interfere with the level of emergence of leadership. In addition, when the case study is not multiple, the findings are even less easily generalizable. Other limitations are related to bias in the speech. Indeed, several members of the MigrAction Strategy were interviewed a few years after the end of their involvement. Their memories and perceptions might have changed in the meantime.

Finally, it should be noted that the study of the emergence of leadership has only demonstrated the individual dimension of organizational leadership. There is also a holistic form of organizational leadership. Its emergence process is different since each actor has to interiorize a speech and organizational goals. It is therefore necessary to know precisely the emergence of both individual and holistic leaderships and the extent of their compatibility.

\section{Acknowledgements}

A special thanks to James McDonald for his valuable comments on the form.

\section{References}

Aebischer, V., \& Oberlé, D. (2007). Le groupe en psychologie sociale. Paris: Dunod.

Barker, A. M. (1991). An Emerging Leadership Paradigm: Transformational Leadership. Nursing \& Health Care, 12(4), 204-207.

Barker, L. L., Wahlers, K. J., \& Watson, J. W. (1987). Groups in Process: An Introduction To Small Group Communication. Englewood Cliffs: Prentice-Hall. 
Beaud, J. P. (2006). L'échantillonnage. In B. Gauthier (Ed), Recherche sociale: De la problématique à la collecte des données (pp. 251-283). Sainte-Foy: Presses de l’Université du Québec.

Blanchet, A., \& Gotman, A. (2006). L'enquête et ses méthodes. L'entretien. Paris: Armand Colin.

Bourque, D. (2008). Concertation et partenariat. Entre levier et piège du développement des communautés. Québec: PUQ.

Forsyth, D. R. (1990). Group Dynamics. Pacific Grove: Brooks/Cole. http://dx.doi.org/10.4135/9781412956253.n239

Friedmann, J. (1992). Empowerment: The Politics of Alternative Development. Oxford: Blackwell. http://dx.doi.org/10.2307/143732

Ghiglione, R., Matalon, B., \& Bacri, N. (1985). Les dires analysés. L'analyse propositionnelle du discours. Paris: Presses Universitaires de Vincennes.

Gumuchian, H., Grasset, E., Lajarge, R. et Roux, E. (2003). Les acteurs, ces oubliés du territoire. Paris: Economica.

Joyal, A. (2002). Le développement local, comment stimuler l'économie des régions en difficulté. Québec: Presses de l’Université Laval.

Lainey, P. (2008). Le leadership organisationnel. De la théorie à la pratique. Montréal: Chenelière Éducation.

Lefebvre, H. (1974). La production de l'espace. Paris: Anthropos.

Lemieux, V. (1999). Les réseaux d'acteurs sociaux. Paris: Presses Universitaires de France.

Luc, É. (2004). Le leadership partagé: Modèle d'apprentissage et d'actualisation. Montréal: Les Presses de l'Université de Montréal.

Prévost, P. (1996). Le leadership local et le développement: quelques réflexions. Sherbrooke: Université de Sherbrooke.

Proulx, M.-U. (2007). Vision 2025 : le Saguenay - Lac-Saint-Jean face à son avenir. Québec: PUQ.

Roy, N. S. (2009). L'étude de cas. In B. Gauthier (Ed.), Recherche sociale : De la problématique à la collecte des données (pp. 199-225). Sainte-Foy: PUQ.

Stecq, H. (2014). La mobilisation des réseaux d'acteurs et le développement regional : Le cas de la Stratégie MigrAction au Saguenay - Lac-Saint-Jean (Québec) (Unpublished doctoral dissertation). University of Quebec at Chicoutimi, Chicoutimi.

Touraine, A. (1992). Critique de la modernité. Paris: Fayard.

Wils, T., Labelle, C., Guérin, G., \& Tremblay, M. (1998). Qu'est-ce que la «mobilisation» des employés. Revue Internationale de Gestion, 23(2), 30-39.

Yin, R. (2003). Case Study Research: Design and Methods. Thousand Oaks: Sage Publications.

\section{Notes}

Note 1. French term to designate the person who relays information.

Note 2. 23 out of the 24 identified actors were interviewed, which guaranteed access to quality information. Nevertheless, the small number of population cannot lead to a generalization of the case.

Note 3. Youth Action Grouping.

Note 4. Regional Conference of Elected. 